Published in final edited form as:

Adv Healthc Mater. 2015 January 07; 4(1): 87-97. doi:10.1002/adhm.201400264.

\title{
A Pharmacokinetic Model of a Tissue Implantable Insulin Sensor
}

\author{
Gili Bisker, \\ Department of Chemical Engineering, Massachusetts Institute of Technology, 77 Massachusetts \\ Avenue, Cambridge, Massachusetts 02139, USA \\ Nicole M. Iverson, \\ Department of Biological Engineering, Massachusetts Institute of Technology, 77 Massachusetts \\ Avenue, Cambridge, Massachusetts 02139, USA
}

Jiyoung Ahn, and

Department of Chemical Engineering, Massachusetts Institute of Technology, 77 Massachusetts Avenue, Cambridge, Massachusetts 02139, USA

\section{Michael S. Strano}

Department of Chemical Engineering, Massachusetts Institute of Technology, 77 Massachusetts Avenue, Cambridge, Massachusetts 02139, USA

\section{Abstract}

\begin{abstract}
While implantable sensors such as the continuous glucose monitoring system have been widely studied, both experimentally and mathematically, relatively little attention has been applied to the potential of insulin sensors. Such sensors could provide feedback control for insulin infusion systems and pumps, and provide platforms for the monitoring of other biomarkers in vivo. In this work, we develop the first pharmacokinetic model of an affinity sensor for insulin operating subcutaneously in the limit of where mass transfer across biological membranes reaches a steady state. Using a physiological, compartmental model for glucose, insulin, and glucagon metabolism, the maximum sensor response and its delay time relative to plasma insulin concentration, are calculated based on sensor geometry, placement, and insulin binding parameters for a sensor localized within adipose tissue. A design relation is derived linking sensor dynamics to insulin time lag and placement within human tissue. The model should find utility in understanding dynamic insulin responses and forms the basis of model predictive control algorithms that incorporate sensor dynamics.
\end{abstract}

\section{Graphical Abstract}

Supporting Information

Supporting Information is available from the Wiley Online Library or from the author. 


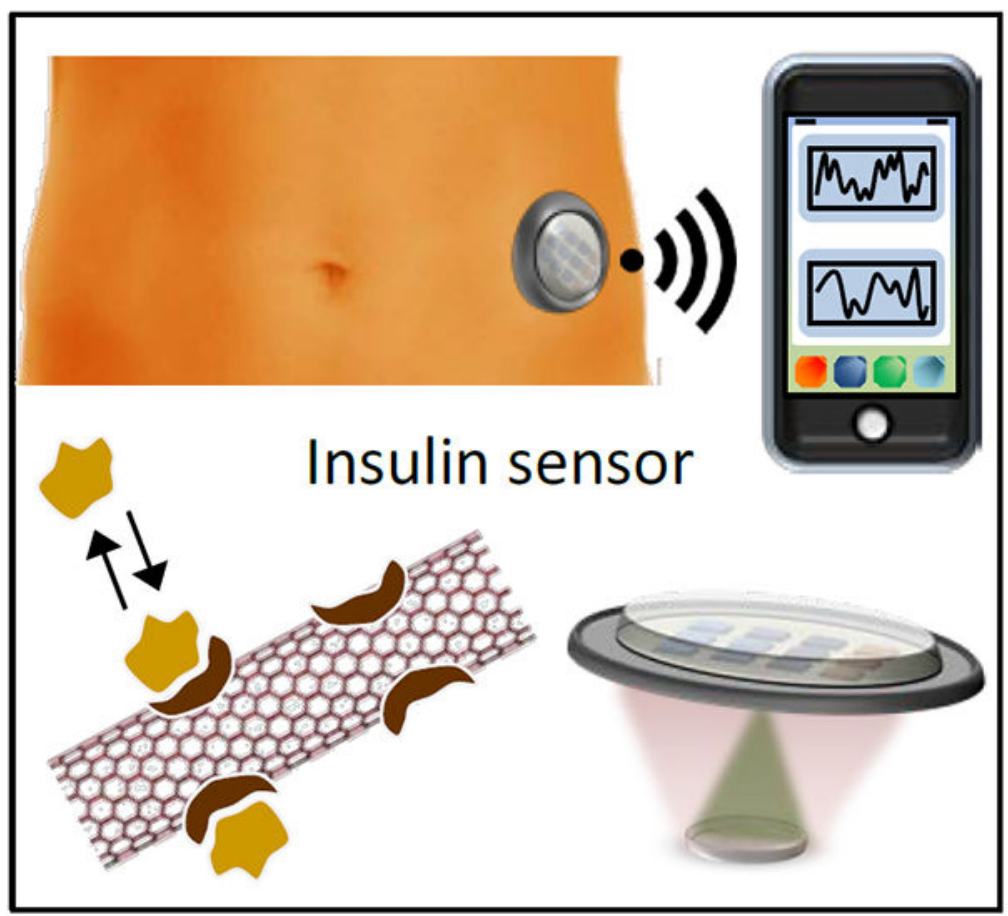

\section{The table of contents entry}

In vivo insulin affinity sensor is modeled and optimized using a full physiological compartmental model for glucose, insulin and glucagon metabolism. The detection platform is based on fluorescent sensors encapsulated within a hydrogel implanted subcutaneously enabling external optical detection. We explicate the correlation between insulin - sensor interaction parameters and hydrogel dimensions to the sensor response and time lag relative to plasma concentration, providing theoretical grounds for experimental designs.

\section{Keywords}

insulin sensors; single-walled carbon nanotubes

\section{Introduction}

Insulin is a $5.8 \mathrm{kDa}$ naturally occurring hormone, synthesized and secreted by pancreatic $\beta$ cells, and is part of the glucose homeostasis regulation system in the body. Impaired glucose metabolism occurs in diabetes mellitus ${ }^{[1]}$, which is a metabolic disease affected by nearly 26 million people in the United States alone. Approximately $90 \%$ of diabetes cases are of type II (non-insulin-dependent), characterized by insulin resistance and partial insulin deficiency, whereas type I diabetes (insulin-dependent) is characterized by destruction of the insulin producing cells resulting in a complete insulin deficiency ${ }^{[1]}$. Patients who suffer from type I diabetes, rely on various insulin drugs administered on a daily basis based on the transient glucose level ${ }^{[2]}$. Continuous glucose monitoring (CGM) along with insulin pump infusion was proven to be a better course of treatment for insulin-dependent diabetes than injection treatment, in terms of glycated hemoglobin level ${ }^{[3]}$ (which correlates to the average glucose 
levels of the previous $2-3$ months $^{[4]}$ ), and was shown to decrease hypoglycemia event ${ }^{[5]}$. Recent technological advantages have led to an FDA approved insulin pump that includes CGM in real time and an automated subcutaneous insulin infusion pump that stops when blood glucose levels drop below a certain threshold (MiniMed 530G, Medtronic Inc.). However, insulin levels are not monitored in real time in such automated systems and the insulin dosage is determined by a proportional-integrative-derivative (PID) control algorithm solely based on the glucose levels ${ }^{[5 b, 6]}$.

Continuous insulin monitoring (CIM) can accompany the PID control algorithm of the closed loop system, providing additional regulation to its control. If available, CIM can recognize patient specific elevated insulin levels, which increase the risk of hypoglycemia in type I diabetes patients who are treated with an insulin pump. Moreover, it can be utilized for diagnosing complications. For example, fasting insulin levels can be used as a marker for insulin resistance ${ }^{[7]}$, which can occur in both type I and type II diabetes ${ }^{[8]}$. Insulin levels can also monitor progression of $\beta$-cell dysfunction in type II diabetes, and insulin response to glucose infusion in insulin-resistant patients can be used to assess their insulin sensitivity[9].

Normal fasting concentration levels of insulin in blood range between $50-80 \mathrm{pM}^{[10]}$, hence requiring highly sensitive and selective detection and quantification. Insulin concentrations in blood samples were first detected by radioimmunoassay ${ }^{[11]}$, which was later replaced by an enzyme-linked immunosorbent assay ${ }^{[12]}$. Other methods include quartz crystal microbalance $(\mathrm{QCM})^{[10]}$, electrochemical impedance spectroscopy (EIS) ${ }^{[13]}$, surface plasmon resonance $(\mathrm{SPR})^{[14]}$, carbon nanotube modified electrode ${ }^{[15]}$, and nickel powder modified electrode ${ }^{[16]}$. Additional approaches utilize QCM transducers and molecularly imprinted polymers either by insulin or an insulin antibody; however the detection limit is in the $\mathrm{mM}$ range ${ }^{[17]}$. Alternative methods include imaging ellipsometry of an insulin antibody modified gold surface ${ }^{[18]}$, fluorescent imaging of fluorescently labeled insulin binding aptamer immobilized on graphene oxide ${ }^{[19]}$, and hyperspectral Raman spectroscopy of human islets of Langerhans ${ }^{[20]}$.

Recently, our group has presented a new concept for analyte detection utilizing the corona phase of a polymer wrapped nanoparticle for molecular recognition, CoPhMoRe ${ }^{[21]}$. Here, the polymer adopts a configuration such that recognition of a specific molecule is enabled, rendering the nanoparticle configuration a 'synthetic antibody'. When applied to the surface of semiconducting single walled carbon nanotubes, which fluoresce in the near infrared range, the result is a fluorescent sensor for the target analyte utilizing either the intensity change or a wavelength shift of the emission for detection ${ }^{[22]}$. Moreover, our group has recently demonstrated the feasibility of in vivo detection using a biocompatible hydrogel for single walled carbon nanotubes (SWNT) sensor encapsulation and subcutaneous implantation ${ }^{[23]}$. The unique optical and electronic properties of SWNT ${ }^{[24]}$ render them favorable as in vivo fluorescent imaging agents ${ }^{[25]}$ owing to their fluoresce in the near infrared range ${ }^{[26]}$, where tissue and blood are mostly transparent ${ }^{[27]}$, and their lack of photobleaching ${ }^{[28]}$.

In this work we present a theoretical model for designing an in vivo insulin sensor for continuous, real time, detection of insulin. The proposed sensor is based on a tailored 
polymer - fluorescent sensor complex capable of optically detecting insulin selectively. The sensor is encapsulated within a biocompatible hydrogel implanted in the subcutaneous adipose tissue, where its presumed near infrared fluorescence allows for external noninvasive optical detection (Figure 1). Although hydrogels have been implanted in vivo in many tissue types, including bone ${ }^{[29]}$, liver ${ }^{[30]}$, pancreas ${ }^{[31]}$, kidneys ${ }^{[32]}$, muscle ${ }^{[33]}$, intestines ${ }^{[34]}$, and subcutaneous tissue ${ }^{[35]}$, the latter is the most accessible for external measurements ${ }^{[23]}$.

We use a full physiological compartmental model of glucose, insulin, and glucagon metabolism, based on the model of Sorensen et al. ${ }^{[36]}$. This model includes 22 differential equations for describing the various compartments in the human body, including the brain, heart and lungs, gut, liver, kidney, and periphery. In order to predict insulin levels in adipose interstitial volume, where the proposed sensor would be implanted, we have divided the periphery compartment into two separate subcompartments of muscle tissue and adipose tissue, extending the model to a total of 26 coupled ordinary differential equations for the transient insulin, glucose, and glucagon concentrations. We then model insulin diffusion into the hydrogel and the response of the embedded insulin sensors, optimizing the gel, sensor, and interaction parameters for optimal insulin in vivo detection.

\section{Theoretical basis}

The insulin metabolism cannot be decoupled from the glucose and glucagon concentrations in the body. For example, the glucose uptake in the periphery interstitial volume as well as in the liver is regulated by the local insulin concentration. Moreover, hepatic glucose production is regulated by both the local insulin and glucagon concentrations, and the pancreas insulin release is regulated by glucose blood levels. Therefore, a complete physiological model requires consideration of all transient concentrations of glucose, insulin and glucagon.

Our analysis follows that of Sorensen et al. ${ }^{[36]}$ by dividing the human body into isochoric compartments, including the capillary volume and the interstitial volume, and allowing for the solute to flow into and out of each compartment with mass transport between them. The solute convectively travels from the arterial blood to the capillary volume $V_{C}$, with rate $Q_{C}$, from which it can diffuse to the interstitial volume $V_{S}$ with characteristic transcapillary diffusion time $T$. Moreover, metabolic sources and sinks can give rise to additional accumulation or depletion of the solute. The mass balance can be written as follows:

$$
V_{C} \frac{d C_{C B}}{d t}=Q_{C}\left(C_{A B}-C_{C B}\right)+\frac{V_{S}}{T}\left(C_{S}-C_{C B}\right)-r_{R B C U}
$$

and

$$
V_{S} \frac{d C_{S}}{d t}=\frac{V_{S}}{T}\left(C_{C B}-C_{S}\right)-r_{T}
$$


where $C_{A B}, C_{C B}$, and $C_{S}$ are the solute concentrations in the arterial blood, capillary blood, and the interstitial fluid respectively, and $r_{R B C U}$ and $r_{T}$ are the rates of solute uptake by red blood cells and the tissue, respectively. Rapid transcapillary diffusion allows for the capillary and interstitials volumes to be considered as one compartment and to be described by a single equation. This is the case for the heart and lungs, liver, gut, and kidney in both the glucose and insulin subsystems ${ }^{[36]}$. The brain and periphery compartments are divided into the capillary volume and the interstitial volume, and are described by two equations similar to Equation (1) and (2), with the exception of the brain cerebrospinal fluid which is impermeable to insulin and thus omitted from the equations ${ }^{[36]}$. Compared to glucose, which is a small molecule that can exhibit rapid blood clearance ${ }^{[37]}$, insulin is a small peptide that is presumably less permeable by the capillary wall. However, past studies have shown that the capillaries in the liver, kidney and gut are more permeable to insulin than in the periphery, confirming that each of those organs can be combined into a single compartment in the model ${ }^{[36]}$.

Our compartmental model, in which we have modified the original Sorensen model by dividing the periphery compartment into muscle and adipose tissue, is illustrated in Figure 2. The variables in this model are summarized in Table 1.

The corresponding new variables must obey the following relations for both the glucose and insulin subsystems:

$$
\begin{aligned}
& V_{M P}+V_{A P}=V_{P} \\
& Q_{M P}+Q_{A P}=Q_{P}
\end{aligned}
$$

where the ratio between the corresponding blood flow rate was estimated using the work of Mapleson ${ }^{[38]}$, who considered blood flow rates in the various body compartments for modeling the distribution of inhaled inert gases:

$$
\frac{Q_{M P}}{Q_{A P}}=2.5
$$

\subsection{Glucose system}

The new equations for the vascular and interstitial compartments of muscle and adipose tissue, respectively, in the glucose system are: 


$$
\begin{aligned}
& V_{M P V}^{G} \frac{d G_{M P V}}{d t}=Q_{M P}^{G}\left(G_{H}-G_{M P V}\right)-\frac{V_{M P I}^{G}}{T_{M P}^{G}}\left(G_{M P V}-G_{M P I}\right) \\
& V_{M P I}^{G} \frac{d G_{M P I}}{d t}=\frac{V_{M P I}^{G}}{T_{M P}^{G}}\left(G_{M P V}-G_{M P I}\right)-r_{M P G U} \\
& V_{A P V}^{G} \frac{d G_{A P V}}{d t}=Q_{A P}^{G}\left(G_{H}-G_{A P V}\right)-\frac{V_{A P I}^{G}}{T_{A P}^{G}}\left(G_{A P V}-G_{A P I}\right) \\
& V_{A P I}^{G} \frac{d G_{A P I}}{d t}=\frac{V_{A P I}^{G}}{T_{A P}^{G}}\left(G_{A P V}-G_{A P I}\right)-r_{A P G U}
\end{aligned}
$$

The relations to the original parameters in the Sorensen models are:

$$
\begin{aligned}
& V_{M P V}^{G} G_{M P V}+V_{A P V}^{G} G_{A P V}=V_{P V}^{G} G_{P V} \\
& V_{M P I}^{G} G_{M P I}+V_{A P I}^{G} G_{A P I}=V_{P I}^{G} G_{P I}
\end{aligned}
$$

and:

$$
r_{M P G U}+r_{A P G U}=r_{P G U}
$$

where muscle and adipose tissues are responsible for $89 \%$ and $11 \%$ of the total periphery glucose uptake ${ }^{[39]}, r_{P G U}$, respectively, so $r_{M P G U}=0.89 \times r_{P G U}$ and $r_{A P G U}=0.11 \times r_{P G U}$. Estimation of the corresponding volumes and blood flows in the vascular blood volume was performed using the relations in equations (3) and (4), and by assuming:

$$
\frac{V_{M P V}^{G}}{Q_{M P}^{G}}=\frac{V_{A P V}^{G}}{Q_{A P}^{G}}=\frac{V_{P V}^{G}}{Q_{P}^{G}}
$$

where $V_{P V}^{G}$ and $Q_{P}^{G}$ are parameters of the original Sorensen model. For the interstitial volume we assume:

$$
\frac{V_{M P I}^{G}}{V_{M P V}^{G}}=\frac{V_{A P I}^{G}}{V_{A P V}^{G}}=\frac{V_{P I}^{G}}{V_{P V}^{G}}
$$

and set:

$$
T_{M P}^{G}=T_{A P}^{G}=T_{P}^{G}
$$


where $V_{P I}^{G}$ and $T_{P}^{G}$ are parameters of the original Sorensen model.

Finally, the equation for the heart and lungs, which closes the circulatory blood loop, becomes:

$V_{H}^{G} \frac{d G_{H}}{d t}=Q_{B}^{G} G_{B V}+Q_{L}^{G} G_{L}+Q_{K}^{G} G_{K}+\left(Q_{M P}^{G} G_{M P V}+Q_{A P}^{G} G_{A P V}\right)-Q_{H}^{G} G_{H}-r_{R B C U}+r_{I V G}$

\subsection{Insulin system}

The new equations for the vascular and interstitial compartments of the muscle and adipose tissue, respectively, in the insulin system are:

$$
\begin{aligned}
& V_{M P V}^{I} \frac{d I_{M P V}}{d t}=Q_{M P}^{I}\left(I_{H}-I_{M P V}\right)-\frac{V_{M P I}^{I}}{T_{M P}^{I}}\left(I_{M P V}-I_{M P I}\right) \\
& V_{M P I}^{I} \frac{d I_{M P I}}{d t}=\frac{V_{M P I}^{I}}{T_{M P}^{I}}\left(I_{M P V}-I_{M P I}\right)-r_{M P I C} \\
& V_{A P V}^{I} \frac{d I_{A P V}}{d t}=Q_{A P}^{I}\left(I_{H}-I_{A P V}\right)-\frac{V_{A P I}^{I}}{T_{A P}^{I}}\left(I_{A P V}-I_{A P I}\right) \\
& V_{A P I}^{I} \frac{d I_{A P I}}{d t}=\frac{V_{A P I}^{I}}{T_{A P}^{I}}\left(I_{A P V}-I_{A P I}\right)-r_{A P I C}
\end{aligned}
$$

and the equation for the heart and lungs becomes:

$$
V_{H}^{I} \frac{d I_{H}}{d t}=Q_{B}^{I} I_{B}+Q_{L}^{I} I_{L}+Q_{K}^{I} I_{K}+\left(Q_{M P}^{I} I_{M P V}+Q_{A P}^{I} I_{A P V}\right)-Q_{H}^{I} I_{H}+r_{I V I}
$$

The relations to the original parameters in the Sorensen model are:

$$
\begin{aligned}
& V_{M P V}^{I} I_{M P V}+V_{A P V}^{I} I_{A P V}=V_{P V}^{I} I_{P V} \\
& V_{M P I}^{I} I_{M P I}+V_{A P I}^{I} I_{A P I}=V_{P I}^{I} I_{P I}
\end{aligned}
$$

and

$$
r_{M P I C}+r_{A P I C}=r_{P I C}
$$


Since the peripheral insulin uptake rate, $r_{P I C}$, is linearly proportional to the peripheral vascular blood flow rate, we assume:

$$
\begin{aligned}
& r_{M P I C}=\frac{Q_{M P}^{I}}{Q_{P}^{I}} r_{P I C} \\
& r_{A P I C}=\frac{Q_{A P}^{I}}{Q_{P}^{I}} r_{P I C}
\end{aligned}
$$

Similar to the glucose system, we set:

$$
T_{M P}^{I}=T_{A P}^{I}=T_{P}^{I}
$$

The parameter values for a $70 \mathrm{~kg} \mathrm{man}{ }^{[36]}$ and the complete set of equations can be found in the supporting information. For the glucose model, since the water content of blood is about $84 \%$, its corresponding volumes are decreased by $16 \%$ from the total vascular volume ${ }^{[36]}$. For the insulin model, since the average red blood cell volume content of whole blood is about $40 \%$, the blood volumes as estimated for a $70 \mathrm{~kg}$ man were decreased by $40 \%$ from the total vascular volume ${ }^{[36]}$.

\subsection{Meal absorption.}

Following the model of Lehmann and Deutsch ${ }^{[40]}$, the oral glucose absorption rate by the gut, $r_{O G A}$, was assumed to linearly increase up to a maximal gastric emptying rate ${ }^{[36]}, V_{\max }$ $=800 \mathrm{mg} \mathrm{min}^{-1}$, during a time period of $T_{\text {inc }}$ minutes, remain constant for $T_{\max }$ minutes, and then linearly decrease to zero during a time period of $T_{d e c}$ minutes. For a meal of $M_{g}$ grams of glucose, the duration of maximal absorption rate is:

$$
T_{\max }=\operatorname{Max}\left\{\frac{M_{g}}{V_{\max }}-\frac{1}{2}\left(T_{i n c}+T_{d e c}\right), 0\right\}
$$

Where $T_{\text {inc }}=10 \mathrm{~min}, T_{d e c}=60 \mathrm{~min}$, and $\operatorname{Max}\{. .$.$\} refers to the maximal value between the$ two input variables. When $T_{\max }>0$ the oral glucose absorption rate for a meal eaten in time $t_{0}$ is: 


$$
\begin{aligned}
& r_{O G A}=V_{\max } \frac{t-t_{0}}{T_{i n c}}\left[H\left(t-t_{0}\right)-H\left(t-t_{0}-T_{i n c}\right)\right]+ \\
& +V_{\max }\left[H\left(t-t_{0}-T_{i n c}\right)-H\left(t-t_{0}-T_{i n c}-T_{\max }\right)\right]+ \\
& +V_{\max }\left(1-\frac{t-t_{0}-T_{i n c}-T_{\max }}{T_{d i c}}\right)\left[H\left(t-t_{0}-T_{i n c}-T_{\max }\right)-H\left(t-t_{0}-T_{i n c}-T_{\max }-T_{d i c}\right)\right. \\
& ]
\end{aligned}
$$

where $H(t)$ is the Heaviside step function at $\mathrm{t}$.

When $T_{\max }=0$ we assume:

$$
\begin{aligned}
& r_{O G A}=V_{\max }{ }^{\prime} \frac{t-t_{0}}{T_{i n c}{ }^{\prime}}\left[H\left(t-t_{0}\right)-H\left(t-t_{0}-T_{i n c}{ }^{\prime}\right)\right]+ \\
& +V_{\max }{ }^{\prime}\left(1-\frac{t-t_{0}-T_{i n c}{ }^{\prime}}{T_{d i c}{ }^{\prime}}\right)\left[H\left(t-t_{0}-T_{i n c}{ }^{\prime}\right)-H\left(t-t_{0}-T_{i n c}{ }^{\prime}-T_{d i c}{ }^{\prime}\right)\right]
\end{aligned}
$$

where $T_{i n c}{ }^{\prime}: T_{d e c}{ }^{\prime}=1: 6$, and

$$
\frac{T_{i n c}{ }^{\prime}}{T_{i n c}}=\frac{T_{d e c}{ }^{\prime}}{T_{d e c}}=\frac{V_{\max }{ }^{\prime}}{V_{\max }}
$$

such that

$$
\frac{1}{2}\left(T_{i n c}{ }^{\prime}+T_{d e c}{ }^{\prime}\right) V_{\max }{ }^{\prime}=M_{g}
$$

See Figure 3 for illustration of the oral glucose absorption rate by the gut for different scenarios.

\subsection{Insulin sensor kinetics.}

We assume a sensor completely specific to insulin, such as a hypothetical corona phase of a specifically functionalized near infrared fluorescent SWNT for molecular recognition ${ }^{\text {[21a] }}$ of insulin. We model the insulin - sensor association by second order kinetics: 


$$
C_{I}+\theta \underset{k_{-1}}{\stackrel{k}{\rightleftarrows}} \overline{C_{I} \theta}
$$

Where $C_{I}$ is the free insulin concentration in the vicinity of the sensor, $\theta$ is an unoccupied binding site on the sensor, $\overline{C_{I} \theta}$ is the site bound insulin, and $k$ and $k_{-1}$ are the forward and reverse rate constants, respectively. The total binding site concentration $\theta_{T}$, which remains constant, is given by:

$$
\theta_{T}=[\theta]+\left[\overline{C_{I} \theta}\right]
$$

where the brackets represent concentrations of the respective entities.

Using the dissociation constant:

$$
K_{d}=\frac{k_{-1}}{k}=\frac{\left[C_{I}\right][\theta]}{\left[\overline{C_{I} \theta}\right]}
$$

the reaction rate is:

$$
\begin{aligned}
& r=-\frac{d\left[C_{I}\right]}{d t}=k\left[C_{I}\right][\theta]-k K_{d}\left[\overline{C_{I} \theta}\right] \\
& =k\left[C_{I}\right][\theta]-k K_{d}\left(\theta_{T}-[\theta]\right)
\end{aligned}
$$

and

$$
\frac{d\left[\overline{C_{I} \theta}\right]}{d t}=-\frac{d\left[C_{I}\right]}{d t}=-\frac{d[\theta]}{d t}
$$

The sensor fluorescent response is assumed to be linearly proportional[ ${ }^{[21 a]}$ to the relative sensor surface coverage by insulin molecules with the proportion factor $\beta$ :

$$
\frac{F-F_{0}}{F_{0}}=-\beta \frac{\left[\overline{C_{I}}\right]}{\theta_{T}}
$$

where $F$ is the measured fluorescence intensity in the presence of insulin, and $F_{0}$ is the initial intensity. 


\subsection{Hydrogel diffusion.}

We assume a sensor encapsulated within a biocompatible hydrogel ${ }^{[23]}$ and implanted in the subcutaneous adipose tissue for continuous insulin monitoring. The hydrogel is modeled as a thin disk such that its diameter is much larger than its thickness, allowing one to neglect diffusion in the radial direction, and only account for one dimensional diffusion across the gel $^{[41]}$. The insulin concentration within the hydrogel follows the nonhomogeneous diffusion equation:

$$
\frac{\partial C_{I}^{h}}{\partial t}=D \frac{\partial^{2} C_{I}^{h}}{\partial x^{2}}+r
$$

where $C_{I}^{h}$ is the insulin concentration within the hydrogel, $r$ is the sensor - insulin reaction rate, and $D$ is the diffusion coefficient. The boundary condition for the hydrogel is the transient insulin concentration within the interstitial adipose tissue, $I_{A P I}$, and the initial condition is taken to be the basal insulin level in that subcompartment, according to our model.

We define a dimensionless length scale:

$$
z=\frac{x}{L}
$$

where $L$ is the thickness of the gel, and a dimensionless time scale:

$$
\tau=\frac{t}{\tau_{D}}
$$

where $\tau_{D}$ is the characteristic diffusion time:

$$
\tau_{D}=\frac{L^{2}}{D}
$$

The characteristic reaction time of the sensor is then given by:

$$
\tau_{R}=\frac{1}{k \theta_{T}}
$$

and the Thiele modulus is defined as: 


$$
\phi \equiv \frac{\tau_{D}}{\tau_{R}}=\frac{k \theta_{T} L^{2}}{D}
$$

Using the dimensionless concentration

$$
g=\frac{[\theta]}{\theta_{T}}
$$

equation (26), (27) and (29) can be combined to:

$$
\frac{\partial C_{I}^{h}}{\partial \tau}=\frac{\partial^{2} C_{I}^{h}}{\partial z^{2}}-\phi\left[g C_{I}^{h}+K_{d}(1-g)\right]
$$

and

$$
\frac{d g}{d \tau}=-\frac{\phi}{\theta_{T}}\left[g C_{I}^{h}-K_{d}(1-g)\right]
$$

where the sensor response is:

$$
\frac{F-F_{0}}{F_{0}}=-\beta(1-g)
$$

The schematics and parameters of the insulin sensor model are visualized in Figure 4.

\section{Results and discussion}

\subsection{Insulin and glucose dynamics.}

The glucose and insulin levels in the various body compartments, and the normalized glucagon levels, following a meal of $100 \mathrm{~g}$ of glucose at $t=0$ are presented in Figure 5 .

The blood glucose and insulin concentrations in the peripheral adipose vasculature peak after 88 and 115 minutes respectively (Figure 5, panels (i) and (r)), following the beginning of the meal, whereas the interstitial peak concentrations lag by 3 and 7 minutes respectively (Figure 5, panels (j) and (s)), in agreement with previous findings ${ }^{[42]}$. By fitting an exponential function to the peripheral adipose interstice insulin concentration, a characteristic time for tissue insulin response was found to be $\tau_{\text {tissue }}=57 \mathrm{~min}$. 


\subsection{Insulin sensor response.}

We evaluate the dissociation constant of insulin to SWNT by its dissociation constant of adsorption onto a hydrophobic surface ${ }^{[43]} K_{d}=8.3 \mu M$, which is comparable to other SWNT based sensors ${ }^{[21 \mathrm{a}]}$, and the rate constant from the kinetics of anti-insulin antibody binding to insulin ${ }^{[44]} k=1 \times 10^{5} M^{-1} S^{-1}$. The total binding sites concentration was calculated by assessing a $10 \mathrm{mg} \mathrm{L}^{-1} \mathrm{SWNT}$ concentration within the hydrogel, an average nanotube length of $1 \mu \mathrm{m}$, and assuming an insulin binding site every $50 \mathrm{~nm}^{[28]}$. The diffusion coefficient of insulin within the hydrogel was estimated by $D=10^{-6} \mathrm{~cm}^{2} \mathrm{~s}^{-1}$, based on experimental results ${ }^{[41]}$. Choosing a gel thickness of $L=0.5 \mathrm{~mm}$, this set of parameters yields:

$$
\tau_{D}=2.5 \times 10^{3} s
$$

and

$$
\tau_{R}=50 s
$$

assuring that $\tau_{R} \leq \tau_{D} \leq \tau_{\text {tissue }}$ so that the limiting factor would not results from the sensor encapsulation or the sensor reaction.

The diffusion profile of the insulin into the hydrogel is presented in Figure 6a, using the peripheral adipose tissue insulin transient and basal levels as the boundary and initial conditions for equation (36), respectively, (data appear in Figure 5s), and the conversion for insulin concentration ${ }^{[45]} 1 \mathrm{mU} \cdot \mathrm{L}^{-1}=7.174 \mathrm{pM}$.

The relative unbound site concentration according to equation (37) was solved within the hydrogel, where the initial condition, $g_{\text {initial }}$, was calculated from equations (24) and (25):

$$
g_{\text {initial }}=\frac{1}{\frac{C_{I \text { initial }}^{h}}{K_{d}}+1}
$$

where $C_{I \text { initial }}^{h}$ is the basal insulin concentration that was taken as the initial condition for equation (36) as well. The relative bound insulin was calculated from the relative unbound sites. The concentrations of free and bound insulin within the hydrogel were then averaged over the gel thickness for each time point, and are plotted in Figure $6 \mathrm{~b}$ as dashed and solid blue curves, respectively. The time lag between the bound insulin peak concentration and the free insulin peak concentration is 12 seconds, as expected from the short reaction time. The sensor response was calculated according to equation (38), assuming an arbitrary proportion factor $^{[21 \mathrm{a}]}$ of $\beta=1000$, and is plotted in Figure $6 \mathrm{~b}$ (green curve). The maximum sensor response in this case is $23 \%$. The time lag between the sensor response and the insulin concentration in tissue is approximately 4 minutes, resulting in a total time lag of 11 minutes between sensor response and plasma insulin concentration. Choosing a different proportion 
factor, $\beta$, would only affect the scale of the fluorescence response but would not change the shape of the sensor response curve or the sensor delay time.

\subsection{Sensor optimization.}

The parameters of the gel and of the insulin - sensor kinetics were varied one at a time, while keeping the others constant, in order to check their effect on both the sensor delay time relative to tissue concentration and the maximum response, which we wanted to minimalize and maximize, respectively. First, we changed the gel thickness from $300 \mu \mathrm{m}$ to $0.4 \mathrm{~cm}$, keeping the dissociation constant, $K_{d}=8.3 \mu \mathrm{M}$, and the rate constant, $k=1 \times 10^{5} \mathrm{M}$ ${ }^{-1} S^{-1}$, fixed (Figure 7a). As the gel thickness increased, the sensor delay increased from 1.5 minutes to 27 minutes, and the sensor maximum response decreased from $23 \%$ to $12 \%$. The Thiele modulus increases with the gel thickness squared. We can thus conclude that minimizing the gel thickness would be beneficial in terms of both of sensor delay time and the maximum response parameters, and for the following simulations we kept a minimal value of $L=300 \mu \mathrm{m}$.

The dissociation constant $K_{d}$ was varied over three order of magnitude ranging from $0.1 \mu M$ to $100 \mu M$ (Figure $7 \mathrm{~b}$ ). As the $K_{d}$ value increased, the sensor delay time insignificantly increased from 1 minute to 5 minutes. However, the maximum sensor response significantly changed, increasing from $0.2 \%$ to $200 \%$.

Finally, the rate constant $k$ was varied over three orders of magnitude ranging from $10^{3} \mathrm{M}^{-1} \mathrm{~S}$ ${ }^{-1}$ to $10^{6} M^{-1} S^{-1}$ (Figure 7c), where the Thiele modulus increased linearly with the rate constant. Although the maximum sensor response changed insignificantly from $22 \%$ to $23 \%$, the sensor delay reduced from 14 minutes to 1 minute, as the rate constant increased.

The overall sensor delay can be shortened by using other implantation sites. The insulin concentration levels in the brain, heart and lungs, kidney, and gut compartments peak instantaneously with the peripheral vasculature concentration, whereas the liver insulin concentration is 4 minutes ahead and the peripheral interstitial insulin concentrations are delayed by 5 and 7 minutes for muscle and adipose tissue respectively (Figure 5, panels (k)(s)). All tissue delay times are small relative to the overall response time of the insulin concentration in the body following a meal, $\tau_{\text {tissue, }}$ which is of the order of 1 hour ${ }^{[46]}$. Thus the implantation site can be chosen based on its accessibility for maximal external signal collection, which would favor the subcutaneous space. However, given that future technologies allow for minimally invasive and efficient detection of near infrared fluorescent probes in other tissue sites, our robust mathematical model can provide design and developmental information for all sensor in vivo locations.

In order to avoid the diffusion limitation of the sensor response, a gel must be thin enough to allow for rapid insulin diffusion. However, thinner hydrogel implants could lead to lower single to noise ratio and would require highly efficient signal collection. Additional optimization can be achieved by utilizing a gradient thickness hydrogel that would satisfy the requirements of fast response along with high signal to noise ratio. Using the diffusion coefficient of insulin in aqueous solution ${ }^{[41]} D_{a}=2.16 \times 10^{-6} \mathrm{~cm}^{2} \mathrm{~s}^{-1}$ as an upper bound for the diffusion within the hydrogel, the gel thickness must be less than $1 \mathrm{~mm}$ so that the 
characteristic diffusion time $\tau_{D}$ would be of the order of $\tau_{\text {tissue }}$ or less. Moreover, as long as the sensor kinetics are fast enough and $\tau_{R} \leq \tau_{D}$, the sensor kinetics will not affect the time lag, and the sensor can be modeled as in equilibrium. For the maximal diffusion coefficient $D_{a}$, we would require $k \geq 10^{3} M^{-1} S^{-1}$ and $k \geq 1.2 \times 10^{4} M^{-1} S^{-1}$ for $1 \mathrm{~mm}$ and $300 \mu \mathrm{m}$ gel thickness, respectively.

The total insulin binding site concentration, $\theta_{T}$, can be manipulated by varying the concentration of sensors within the hydrogel. Given a particular SWNT based sensor, other parameters such as the average nanotube length, and the linear density of insulin binding sites along the tube, are much more difficult to control and optimize in the synthesis process. An increase or a decreases of sensor concentration by a factor of 2 , resulting in a similar change to the total insulin binding site concentration, does not change the maximum sensor response, and the sensor delay time remains the same within a range of 1 minute.

\section{Conclusion}

We have derived a mathematical model of an insulin affinity sensor encapsulated within a biocompatible hydrogel suitable for implantation in the subcutaneous adipose tissue enabling external optical detection. A possible platform for the implementation of such a sensor is based on molecular recognition of the corona phase of single-walled carbon nanotubes ${ }^{[21 \mathrm{a}]}$. The sensor response and delay time were calculated based on a full physiological model for insulin metabolism which specifically included the adipose tissue, diffusion of the insulin into the hydrogel encapsulating the sensor, and the insulin - sensor interaction according to established models ${ }^{[21 a]}$. For optimal sensor performance, the characteristic diffusion time should be less than the overall metabolism rate of the body in order to avoid diffusion limitations, and the characteristic insulin - sensor interaction time should be less than the diffusion time so the sensor could rapidly equilibrate and would have little additive effect on delay times.

Minimizing the gel thickness has the most profound effect on reducing the sensor delay time while moderately increasing sensor response. Furthermore, decreasing the dissociation constant has a dramatic effect on maximizing the sensor response, where its effect on the delay time is minimal. Finally, increasing the rate constant has a fair effect on decreasing the delay time but almost no effect on the sensor response.

Our model provides a principal basis for the design of an in vivo insulin affinity sensor, and would play a fundamental part in any experimental realization of such sensor. Our findings are essential for in vitro evaluation of an insulin sensor, providing objective criteria for sensor assessment and in vivo performance prediction.

\section{Supplementary Material}

Refer to Web version on PubMed Central for supplementary material. 


\section{Acknowledgements}

This research was supported by the Juvenile Diabetes Research Foundation. G. Bisker acknowledges the TechnionMIT postdoctoral fellowship, J. Ahn is grateful for the support of the Samsung scholarship, and N. M. Iverson thanks the National Institutes of Health T32 Training Grant in Environmental Toxicology ES007020.

\section{REFERENCES}

1. Bascones-Martinez A, Matesanz-Perez P, Escribano-Bermejo M, Gonzalez-Moles MA, BasconesIlundain J, Meurman JH, Med Oral Patol Oral Cir Bucal 2011, 16, e722-729. [PubMed: 21196866]

2. aBinder C, Lauritzen T, Faber O, Pramming S, Diabetes Care 1984, 7, 188-199; [PubMed: 6376015] bLi J, Kuang Y, Math Biosci Eng 2009, 6, 41-58. [PubMed: 19292507]

3. Bergenstal RM, Tamborlane WV, Ahmann A, Buse JB, Dailey G, Davis SN, Joyce C, Peoples T, Perkins BA, Welsh JB, Willi SM, Wood MA, New England Journal of Medicine 2010, 363, 311320. [PubMed: 20587585]

4. Bennett CM, Guo M, Dharmage SC, Diabetic Medicine 2007, 24, 333-343. [PubMed: 17367307]

5. aBattelino T, Conget I, Olsen B, Schütz-Fuhrmann I, Hommel E, Hoogma R, Schierloh U, Sulli N, Bolinder J, Diabetologia 2012, 55, 3155-3162; [PubMed: 22965294] bGifford R, ChemPhysChem 2013, 14, 2032-2044. [PubMed: 23649735]

6. Weinzimer SA, Steil GM, Swan KL, Dziura J, Kurtz N, Tamborlane WV, Diabetes Care 2008, 31, 934-939. [PubMed: 18252903]

7. Laakso M, American Journal of Epidemiology 1993, 137, 959-965. [PubMed: 8317453]

8. aDeFronzo RA, Simonson D, Ferrannini E, Diabetologia 1982, 23, 313-319; [PubMed: 6754515] bGreenbaum CJ, Diabetes Metab Res Rev 2002, 18, 192-200; [PubMed: 12112937] cDonga E, van Dijk M, Hoogma RP, Corssmit EP, Romijn JA, Diabetes Metab Res Rev 2013, 29, 33-38. [PubMed: 22936679]

9. Kahn SE, Diabetologia 2003, 46, 3-19. [PubMed: 12637977]

10. Singh V, Krishnan S, in Meeting Abstracts, The Electrochemical Society, 2013, pp. 2657-2657.

11. aYalow RS, Berson SA, J Clin Invest 1960, 39, 1157-1175; [PubMed: 13846364] bAlbano JDM, Ekins RP, Maritz G, Turner RC, Acta Endocrinologica 1972, 70, 487-509; [PubMed: 5068062] cNakagawa S, Nakayama H, Sasaki T, Yoshino K, Yu YY, Shinozaki K, Aoki S, Mashimo K, Diabetes 1973, 22, 590-600. [PubMed: 4579520]

12. MacDonald MJ, Gapinski JP, Metabolism 1989, 38, 450-452. [PubMed: 2657325]

13. aXu M, Luo X, Davis JJ, Biosensors and Bioelectronics 2013, 39, 21-25; [PubMed: 22840329] bLuo X, Xu M, Freeman C, James T, Davis JJ, Analytical Chemistry 2013, 85, 4129-4134. [PubMed: 23461715]

14. Frasconi M, Tortolini C, F. Botrè, F. Mazzei, Analytical Chemistry 2010, 82, 7335-7342. [PubMed: 20698498]

15. aWang J, Musameh M, Analytica Chimica Acta 2004, 511, 33-36;bWang J, Tangkuaram T, Loyprasert S, Vazquez-Alvarez T, Veerasai W, Kanatharana P, Thavarungkul P, Analytica Chimica Acta 2007, 581, 1-6. [PubMed: 17386417]

16. Salimi A, Roushani M, Soltanian S, Hallaj R, Analytical Chemistry 2007, 79, 7431-7438. [PubMed: 17715992]

17. Schirhagl R, Latif U, Podlipna D, Blumenstock H, Dickert FL, Analytical Chemistry 2012, 84, 3908-3913. [PubMed: 22468696]

18. Bae YM, Oh B-K, Lee W, Lee WH, Choi J-W, Biosensors and Bioelectronics 2004, 20, 895-902. [PubMed: 15522607]

19. Pu Y, Zhu Z, Han D, Liu H, Liu J, Liao J, Zhang K, Tan W, Analyst 2011, 136, 4138-4140. [PubMed: 21874167]

20. Hilderink J, Otto C, Slump C, Lenferink A, Engelse M, van Blitterswijk C, de Koning E, Karperien M, van Apeldoorn A, PLoS ONE 2013, 8, e78148. [PubMed: 24167603]

21. aZhang J, Landry MP, Barone PW, Kim J-H, Lin S, Ulissi ZW, Lin D, Mu B, Boghossian AA, Hilmer AJ, Rwei A, Hinckley AC, Kruss S, Shandell MA, Nair N, Blake S, Sen F, Sen S, Croy 
RG, Li D, Yum K, Ahn J-H, Jin H, Heller DA, Essigmann JM, Blankschtein D, Strano MS, Nat Nano 2013, 8, 959-968; bKruss S, Landry MP, Vander Ende E, Lima BMA, Reuel NF, Zhang J, Nelson J, Mu B, Hilmer A, Strano M, Journal of the American Chemical Society 2013, 136, 713724.

22. aKruss S, Hilmer AJ, Zhang J, Reuel NF, Mu B, Strano MS, Advanced Drug Delivery Reviews 2013, 65, 1933-1950; [PubMed: 23906934] bMu B, Zhang J, McNicholas TP, Reuel NF, Kruss S, Strano MS, Accounts of Chemical Research 2014.

23. Iverson NM, Barone PW, Shandell M, Trudel LJ, Sen S, Sen F, Ivanov V, Atolia E, Farias E, McNicholas TP, Reuel N, Parry NMA, Wogan GN, Strano MS, Nat Nano 2013, 8, 873-880.

24. Bachilo SM, Strano MS, Kittrell C, Hauge RH, Smalley RE, Weisman RB, Science 2002, 298, 2361-2366. [PubMed: 12459549]

25. aBarone PW, Baik S, Heller DA, Strano MS, Nat Mater 2005, 4, 86-92; [PubMed: 15592477] bLiu Z, Tabakman S, Welsher K, Dai H, Nano Res. 2009, 2, 85-120. [PubMed: 20174481]

26. O'Connell MJ, Bachilo SM, Huffman CB, Moore VC, Strano MS, Haroz EH, Rialon KL, Boul PJ, Noon WH, Kittrell C, Ma J, Hauge RH, Weisman RB, Smalley RE, Science 2002, 297, 593-596. [PubMed: 12142535]

27. Wray S, Cope M, Delpy DT, Wyatt JS, Reynolds EOR, Biochimica et Biophysica Acta (BBA) Bioenergetics 1988, 933, 184-192. [PubMed: 2831976]

28. Barone PW, Parker RS, Strano MS, Analytical Chemistry 2005, 77, 7556-7562. [PubMed: 16316162]

29. Nguyen LT, Lee BT, Tissue Eng Part A 2014.

30. Lee JS, Shin J, Park HM, Kim YG, Kim BG, Oh JW, Cho SW, Biomacromolecules 2014, 15, 206218. [PubMed: 24350561]

31. Bollyky PL, Vernon RB, Falk BA, Preisinger A, Gooden MD, Nepom GT, Gebe JA, J Diabetes Res 2013, 2013, 342479. [PubMed: 23971054]

32. Soranno DE, Lu HD, Weber HM, Rai R, Burdick JA, J Biomed Mater Res A 2013.

33. McKeon-Fischer KD, Rossmeisl JH, Whittington A, Freeman JW, Tissue Eng Part A 2014.

34. Deat-Laine E, Hoffart V, Garrait G, Jarrige JF, Cardot JM, Subirade M, Beyssac E, Pharm Res 2013, 30, 721-734. [PubMed: 23093377]

35. aAlexandre N, Ribeiro J, Gartner A, Pereira T, Amorim I, Fragoso J, Lopes A, Fernandes J, Costa E, Santos-Silva A, Santos JD, Mauricio AC, Luis AL, J Biomed Mater Res A 2014;bTokatlian T, Cam C, Segura T, Biomaterials 2014, 35, 825-835. [PubMed: 24210142]

36. Sorensen JT, Ph.D. dissertation, Dept. of Chemical Engineering, Massachusetts Institute of Technology 1985.

37. aOrcutt K, Nasr K, Whitehead D, Frangioni J, Wittrup KD, Mol Imaging Biol 2011, 13, 215-221; [PubMed: 20533093] bOrcutt KD, Rhoden JJ, Ruiz-Yi B, Frangioni JV, Wittrup KD, Molecular Cancer Therapeutics 2012, 11, 1365-1372. [PubMed: 22491799]

38. Mapleson WW, Journal of Applied Physiology 1963, 18, 197-204. [PubMed: 13932730]

39. Jackson RA, Peters N, Advani U, Perry G, Rogers J, Brough WH, Pilkington TRE, Diabetes 1973, 22, 442-458. [PubMed: 4713669]

40. Lehmann ED, Deutsch T, Journal of Biomedical Engineering 1992, 14, 235-242. [PubMed: 1588781]

41. Weber LM, Lopez CG, Anseth KS, Journal of Biomedical Materials Research Part A 2009, 90A, 720-729.

42. aThomé-Duret V, Reach G, Gangnerau MN, Lemonnier F, Klein JC, Zhang Y, Hu Y, Wilson GS, Analytical Chemistry 1996, 68, 3822-3826; [PubMed: 8914483] bBoyne MS, Silver DM, Kaplan J, Saudek CD, Diabetes 2003, 52, 2790-2794; [PubMed: 14578298] cVelho G, Froguel P, Thevenot DR, Reach G, Biomed Biochim Acta 1989, 48, 957-964. [PubMed: 2700068]

43. Sluzky V, Tamada JA, Klibanov AM, Langer R, Proceedings of the National Academy of Sciences 1991, 88, 9377-9381.

44. Berson SA, Yalow RS, The Journal of Clinical Investigation 1959, 38, 1996-2016. [PubMed: 13799922] 
45. Colette C, Percheron C, Pares-Herbute N, Michel F, Pham TC, Brillant L, Descomps B, Monnier L, Int J Obes Relat Metab Disord 2003, 27, 648-656. [PubMed: 12833107]

46. Man CD, Rizza RA, Cobelli C, Biomedical Engineering, IEEE Transactions on 2007, 54, 17401749. 


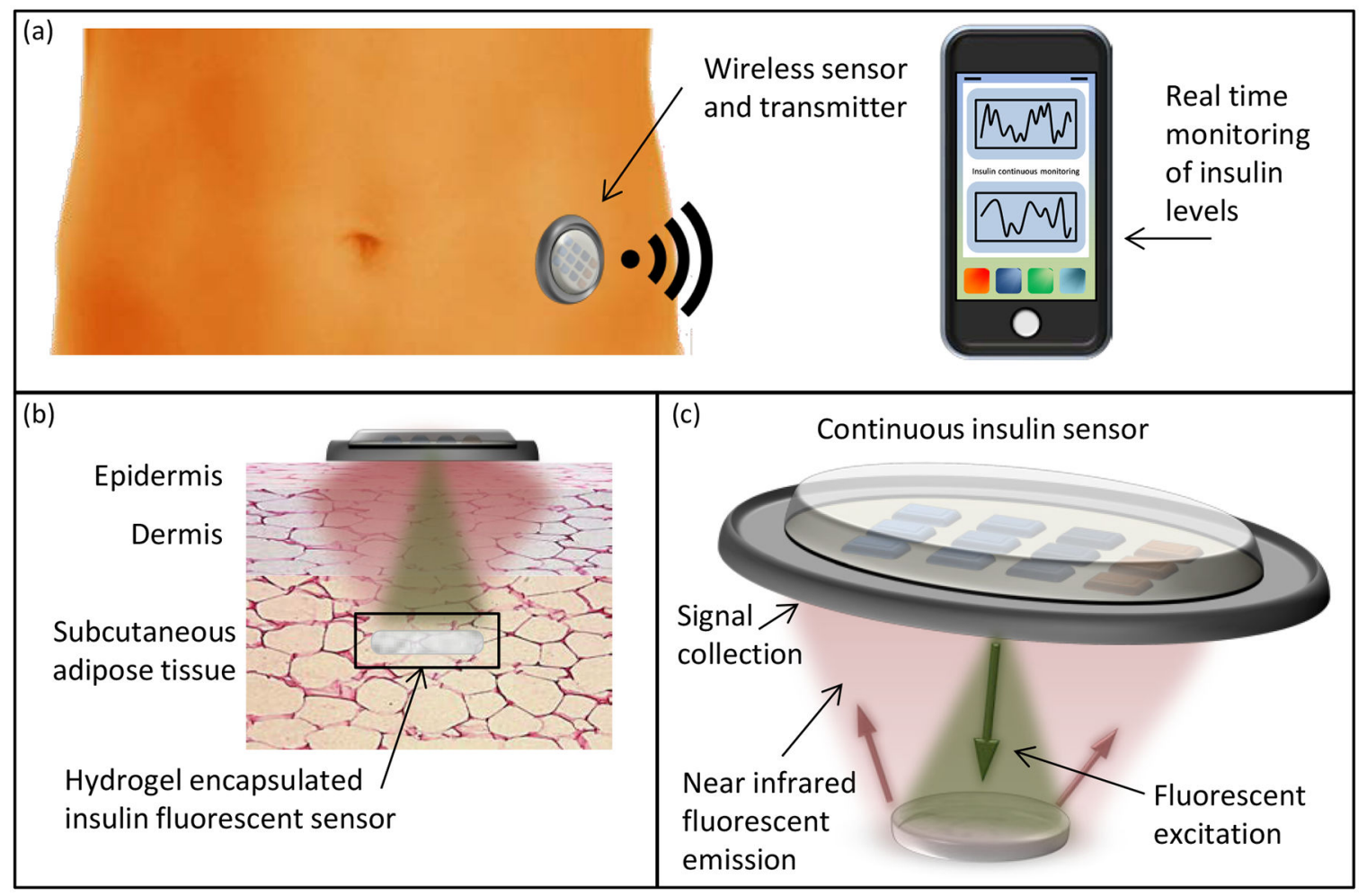

Figure 1.

Illustration of a prototypical optical sensor for insulin implanted in the interstitial subcutaneous adipose tissue. (a) The detection consists of a near infrared fluorescent sensor encapsulated in a hydrogel that is implanted within adipose tissue along with a dermal patch providing optical excitation and collection through the interposed tissue with detection read telemetrically. (b) The sensor is placed at a fixed depth into subcutaneous adipose tissue where (c) the external dermal patch provides optical excitation through the tissue, querying the sensor for insulin concentration, and receiving a proportional emission signal back through the tissue for collection at the patch. 

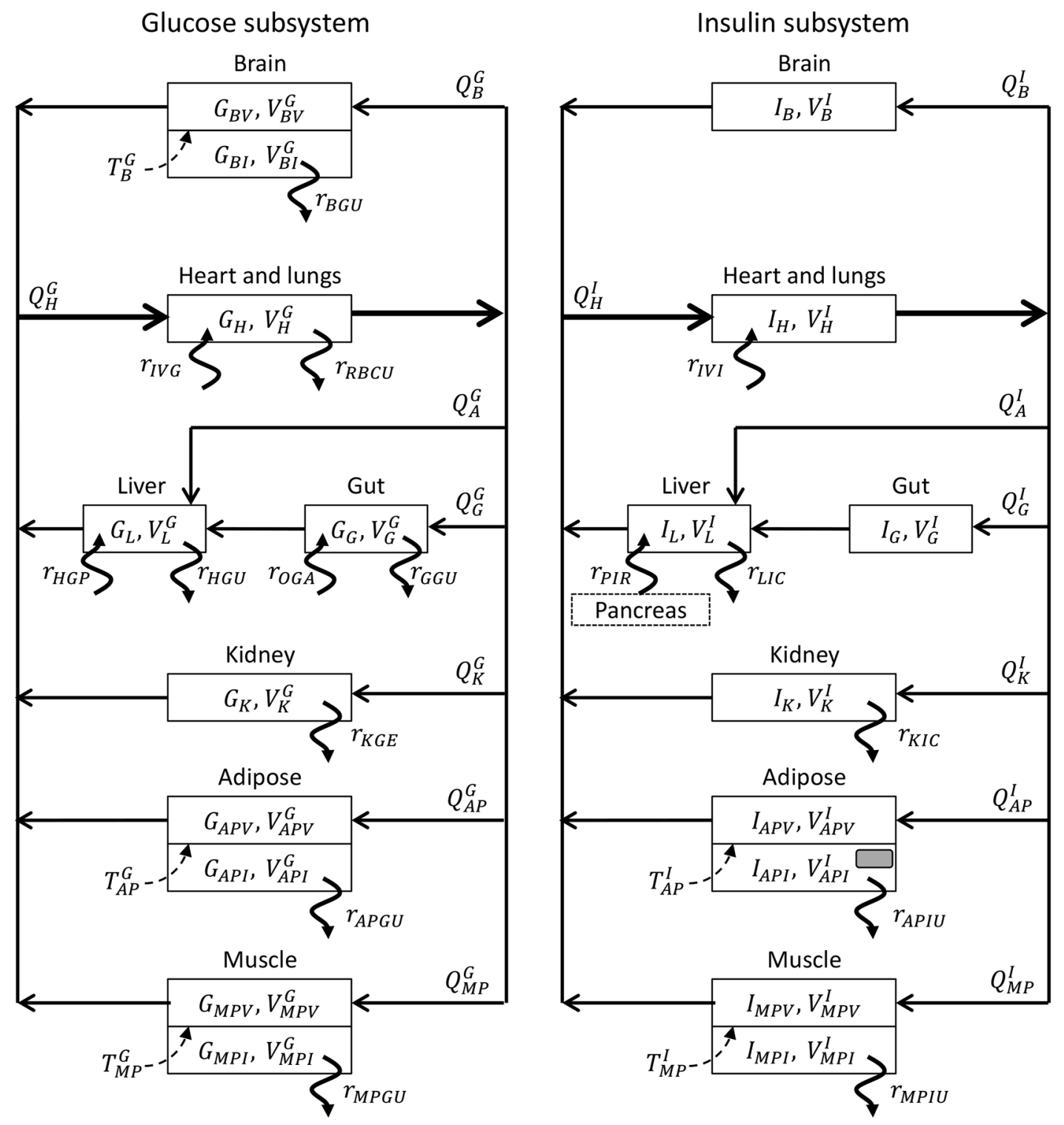

Figure 2.

Compartmental model for glucose (left) and insulin (right) metabolism. The heart and lung compartment represents the cardiopulmonary blood and the major arteries and drain the entire circulatory loop. The arterial blood feeds the capillaries in the gut, liver, kidney, peripheral adipose and muscle tissues, while the liver also receives blood from the hepatic portal vein originating in the gut. The brain in the glucose subsystem and the peripheral adipose and muscle tissues in both the glucose and insulin subsystems, are divided into capillary and interstitial volumes to account for longer transcapillary diffusion times. The insulin sensor represented by a grey rectangle is embedded within the peripheral interstitial adipose volume. See Table 1 for an explanation of each variable. 


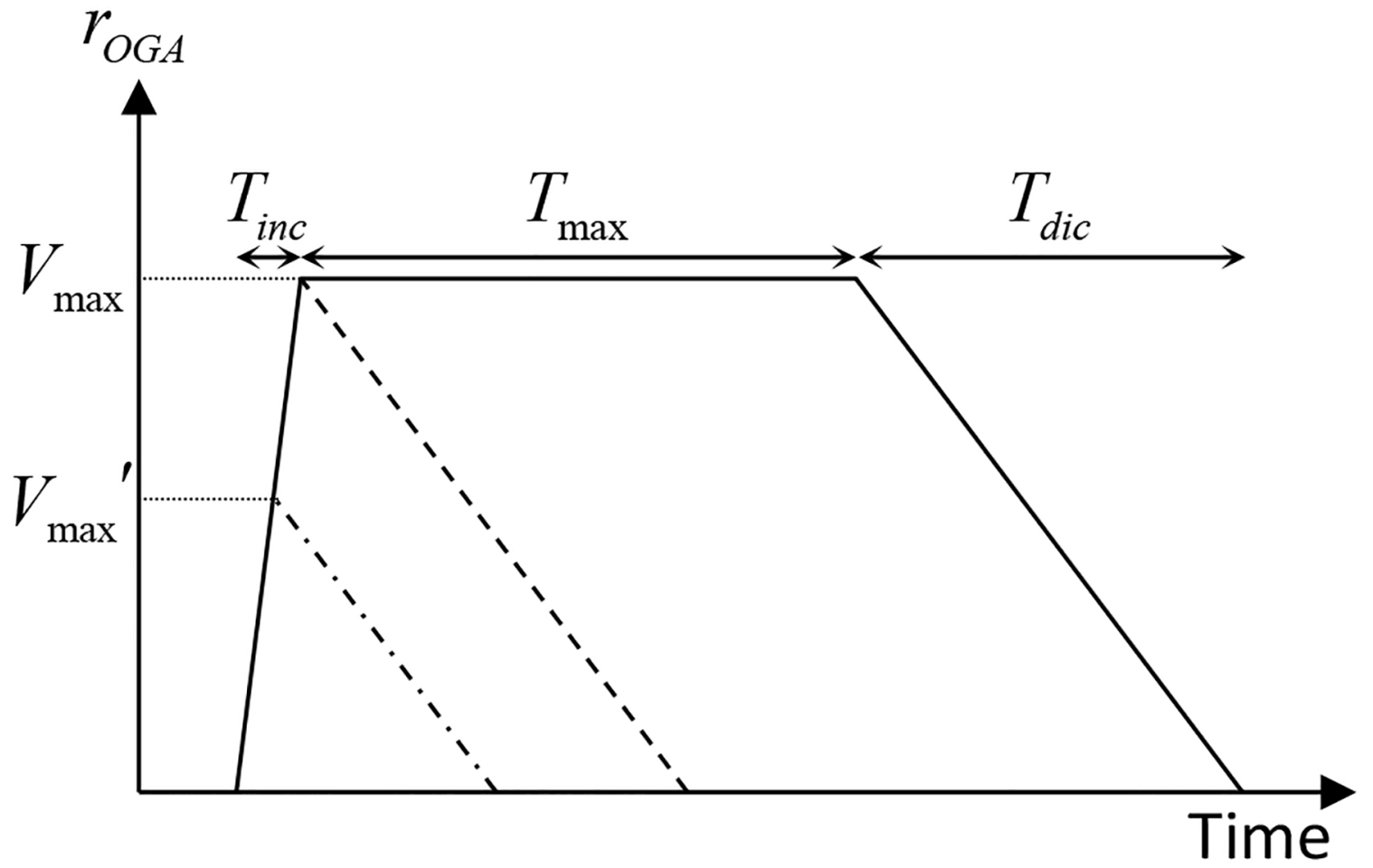

Figure 3.

Oral glucose absorption rate by the gut for $T_{\max }>0$ (solid line), for $V_{\max }{ }^{\prime}=V_{\max }$ (dashed line) and for $V_{\max }{ }^{\prime}<V_{\max }$ (dashed-dotted line). 


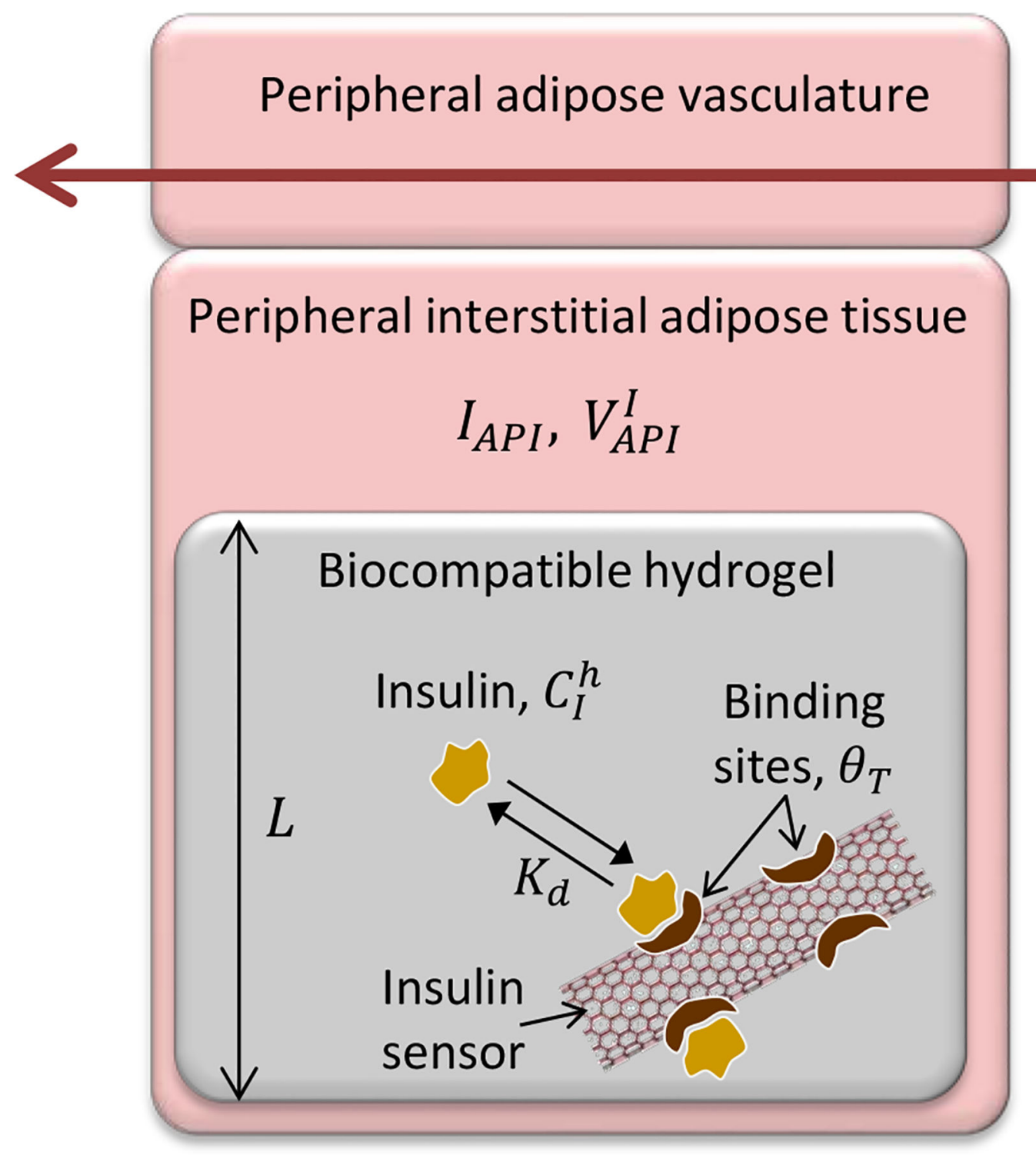

Figure 4.

Implantable insulin sensor schematic. Blood flows in the peripheral adipose vasculature with rate $Q_{A P}^{I}$ from which insulin diffuses into the interstitial tissue of volume $V_{A P I}^{I}$ resulting in transient insulin concentration of $I_{A P I}$ within this volume. Insulin diffuses into the hydrogel of thickness $L$, resulting in transient insulin concentration of $C_{I}^{h}$ within the gel. Insulin sensors are dispersed throughout, having total insulin binding site concentration of $\theta_{T}$, and encapsulated in the hydrogel, where insulin is in equilibrium between free and bound state with a dissociation constant $K_{d}$. 

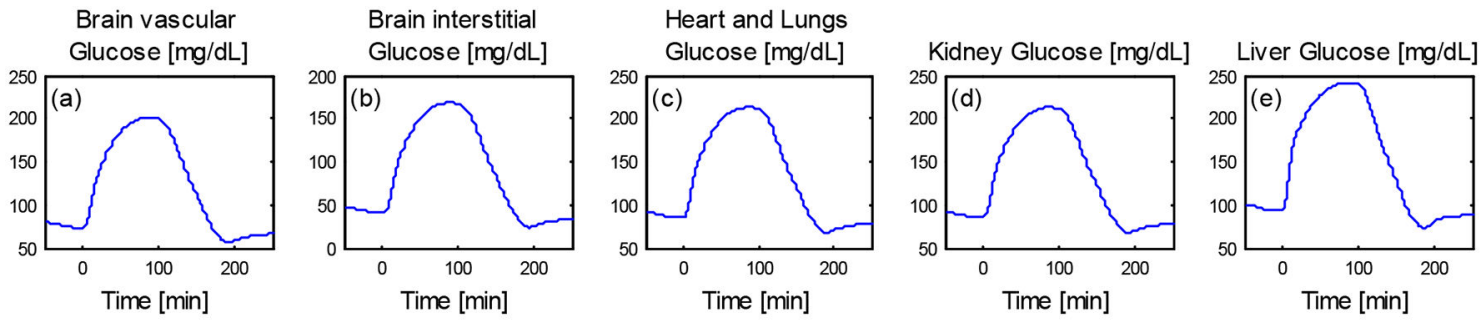

Muscle Periphary

Muscle Periphary

Adipose Periphary

Adipose Periphary
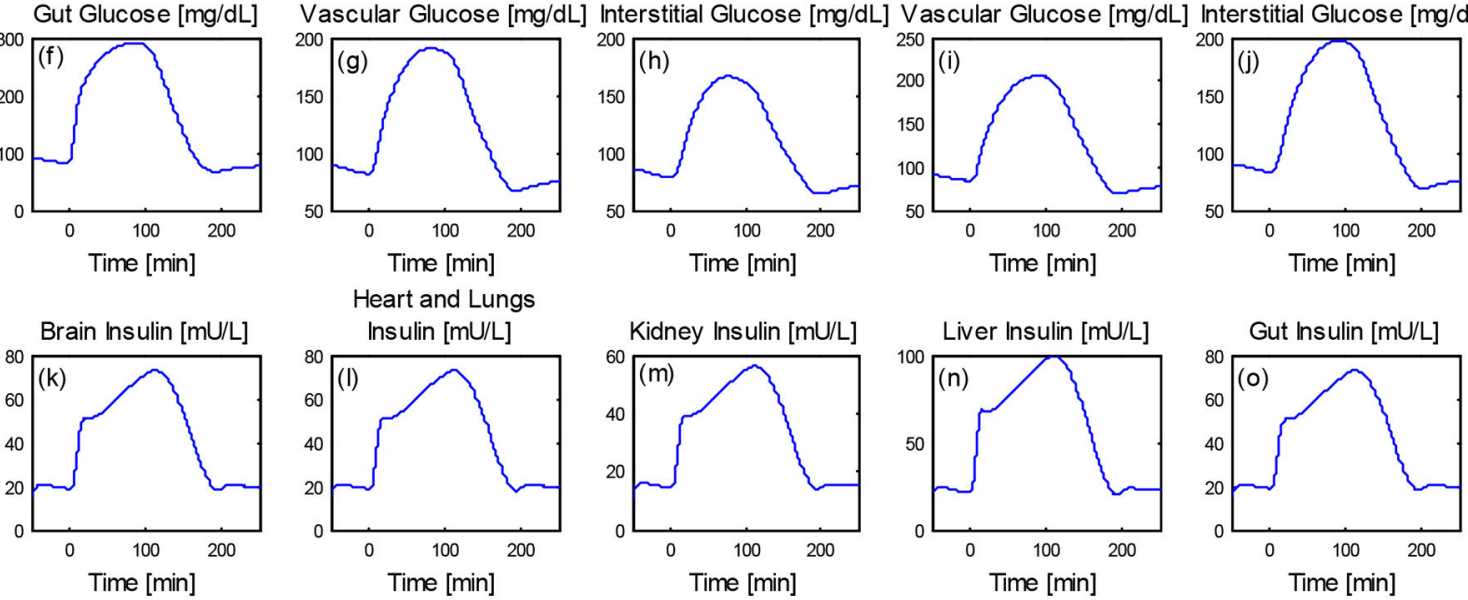

Heart and Lungs
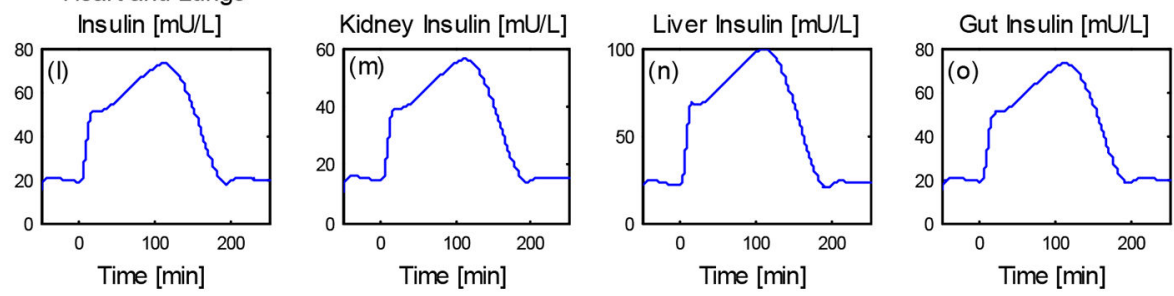

Muscle Periphary

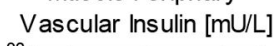

Muscle Periphary

Adipose Periphary
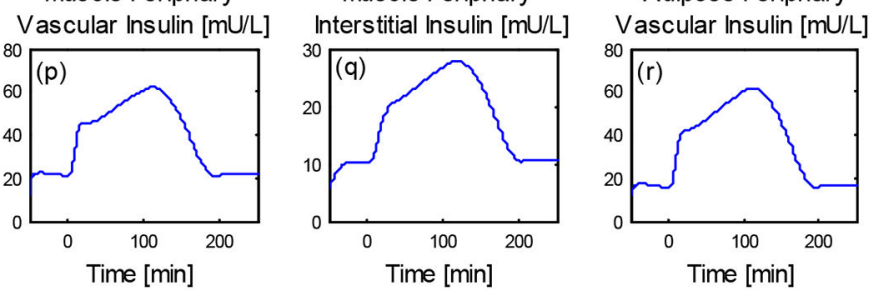

Adipose Periphary
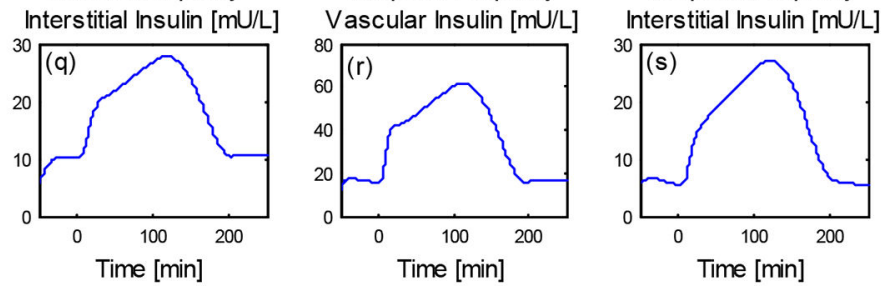

Normalized Plasma glucagon conc.

Figure 5.

Glucose, insulin and glucagon concentrations in the various body compartments following a $100 \mathrm{~g}$ glucose meal at $t=0$ according to our model. (a) - (j) Glucose concentration in (a) Brain vasculature, (b) Brain interstice, (c) Heart and lungs, (d) Kidney, (e) Liver, (f) Gut, (g) Muscle periphery vasculature, (h) Muscle periphery interstice, (i) Adipose periphery vasculature, and (j) Adipose periphery interstice. $(\mathrm{k})$ - ( $\mathrm{s}$ ) Insulin concentration in (k) Brain, (l) Heart and lungs, (m) Kidney, (n) Liver, (o) Gut, (p) Muscle periphery vasculature, (q) Muscle periphery interstice, (r) Adipose periphery vasculature, and (s) Adipose periphery interstice. (t) Normalized glucagon concentration in plasma. 
(a) Insulin concentration in hydrogel [pM]

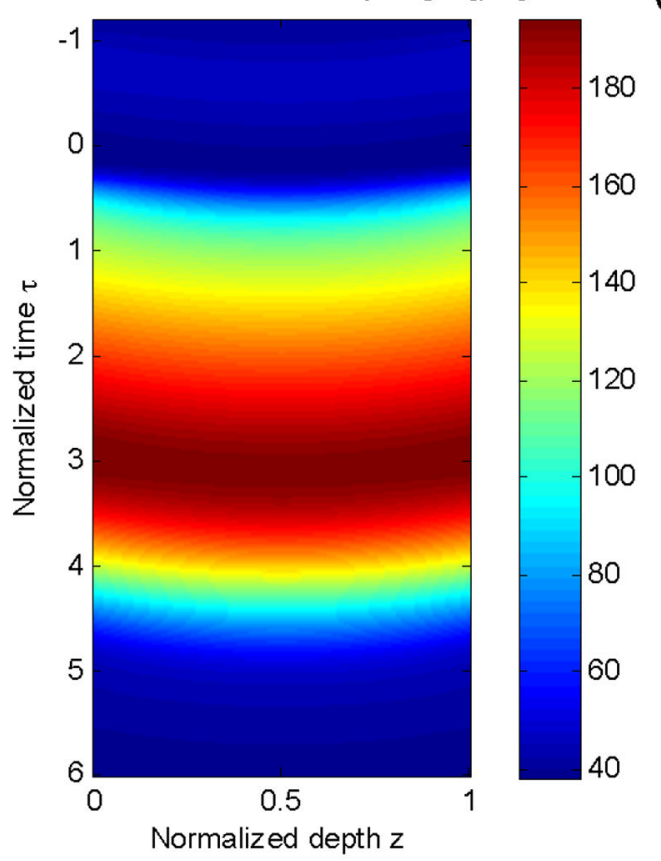

(b)

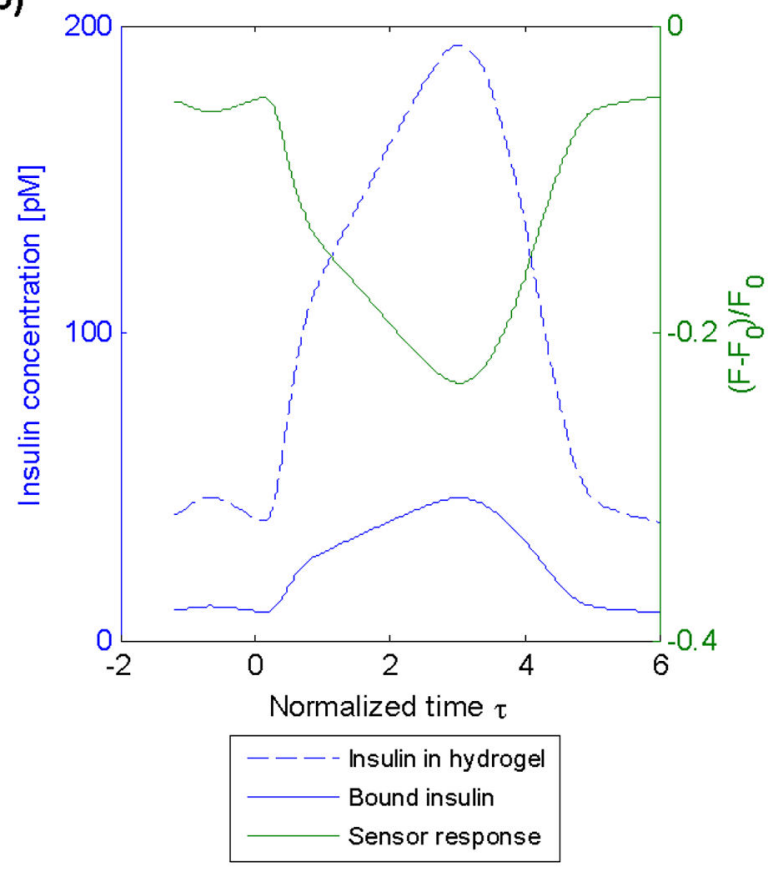

Figure 6.

(a) Insulin concentration within hydrogel encapsulating SWNT insulin sensors, implanted in the subcutaneous adipose tissue, for gel thickness of $L=0.5 \mathrm{~mm}$, Thiele modulus $\phi=50$, diffusion coefficient $D=1 \times 10^{-6} \mathrm{~cm}^{2} \mathrm{~s}^{-1}$, dissociation constant $K_{d}=8.3 \mu \mathrm{M}$, and rate constant $k=1 \times 10^{5} M^{-1} s^{-1}$ following a $100 \mathrm{~g}$ glucose meal according to our model. (b) Averaged insulin concentration within the hydrogel (dashed blue curve), averaged bound insulin concentration (blue curve), and sensor response (green curve). 

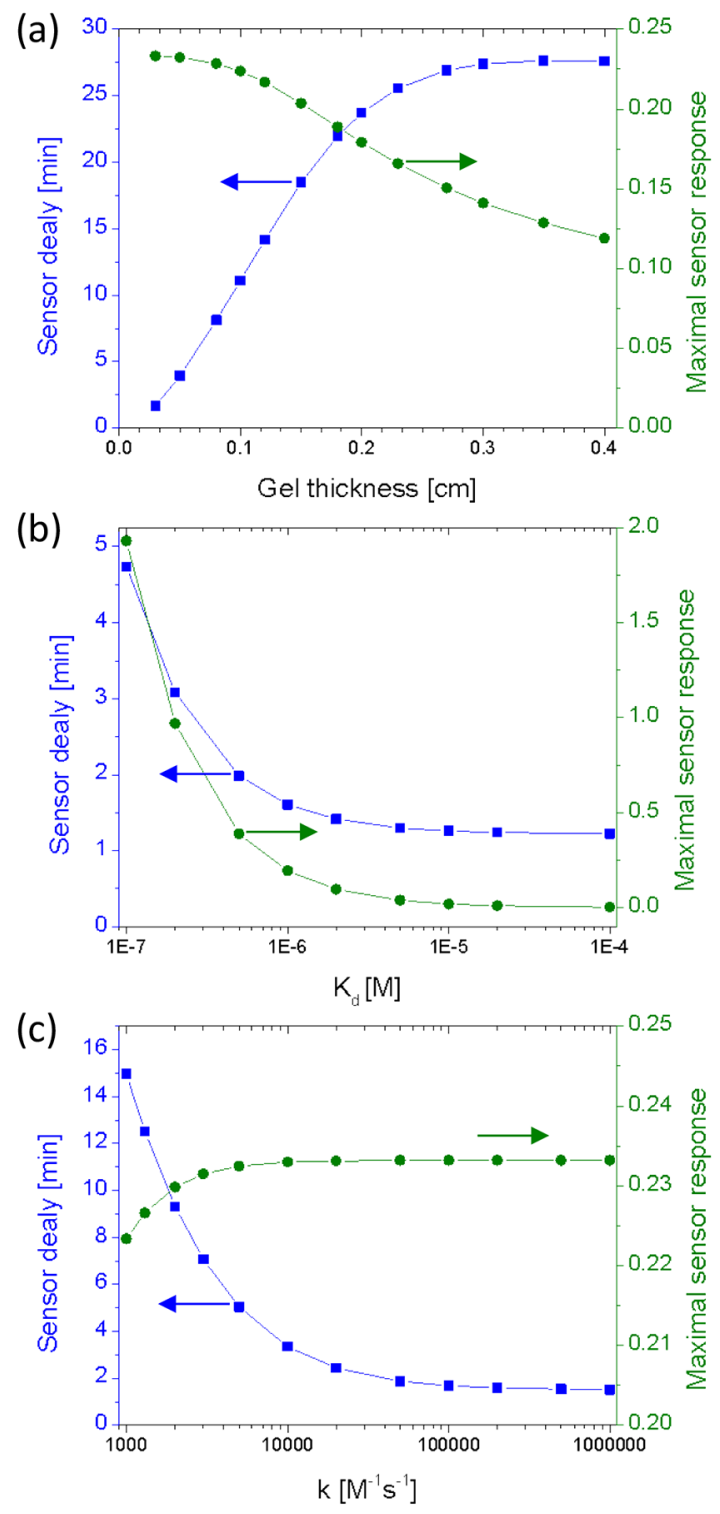

Figure 7.

Insulin sensor delay time (blue curve) with respect to the surrounding tissue concentration and the maximum sensor response (green curve) as a function of (a) the hydrogel thickness, (b) the dissociation constant of the insulin - sensor reaction, and (c) the rate constant of the insulin - sensor reaction, following a $100 \mathrm{~g}$ glucose meal according to our model. The arrows direct each curve to its corresponding y-axis. 
Table 1.

Variables in the modified model.

\begin{tabular}{llll}
\hline \multicolumn{2}{l}{ Variables } & \multicolumn{2}{l}{ Metabolic rates subscripts } \\
G & Glucose concentration & BGU & Brain glucose uptake \\
I & Insulin concentration & RBCU & Red blood cells glucose uptake \\
Q & Vascular blood flow rate & GGU & Gut glucose utilization \\
V & Volume & HGU & Hepatic glucose uptake \\
r & Metabolic source or sink rate & KGE & Kidney glucose excretion \\
T & Transcapillary diffusion time & APGU & Adipose peripheral glucose uptake \\
t & Time & MPGU & Muscle peripheral glucose uptake \\
Compartment - first subscript & IVG & Intravenous glucose infusion \\
B & Brain & OGA & Gut oral glucose absorption \\
H & Heart and lungs & HGP & Hepatic glucose production \\
G & Gut & LIC & Liver insulin clearance \\
L & Liver & KIC & Kidney insulin clearance \\
K & Kidney & APIU & Adipose peripheral insulin uptake \\
P & Periphery & MPIU & Muscle peripheral insulin uptake \\
AP & Adipose periphery & IVI & Intravenous insulin infusion \\
MP & Muscle periphery & PIR & Pancreatic insulin release \\
A & Hepatic artery & & \\
Subcompartment - second subscript & Model - superscript \\
I & Interstitial fluid & G & Glucose \\
V & Vascular blood & I & Insulin \\
\hline
\end{tabular}

